\title{
Multiple independent chromosomal fusions accompanied the radiation of the Antarctic teleost genus Trematomus (Notothenioidei:Nototheniidae)
}

\author{
Juliette Auvinet ${ }^{1,2,3^{*}}$ (D), Paula Graça ${ }^{1,2}$, Agnès Dettai ${ }^{2}$, Angel Amores ${ }^{4}$, John H. Postlethwait ${ }^{4} \mathbb{D}$, \\ H. William Detrich $I I^{3}$ (D), Catherine Ozouf-Costaz ${ }^{1}$, Olivier Coriton ${ }^{5}$ and Dominique Higuet ${ }^{1,2^{*}}$ (D)
}

\begin{abstract}
Background: Chromosomal rearrangements are thought to be an important driving force underlying lineage diversification, but their link to speciation continues to be debated. Antarctic teleost fish of the family Nototheniidae (Notothenioidei) diversified in a changing environmental context, which led to ecological, morphological, and genetic differentiation among populations. In addition, extensive chromosomal repatterning accompanied species divergence in several clades. The most striking karyotypic changes involved the recent species radiation (about $10 \mathrm{My}$ ) of the genus Trematomus, with chromosomal pair numbers ranging between 29 and 12. These dramatic reductions in chromosome number resulted mostly from large-scale chromosome fusions. Multiple centric and/or tandem fusions have been hypothesized in at least seven of the twelve recognized Trematomus species. To reconstruct their evolutionary history, we employed comparative cytogenomics (BAC-FISH and chromosome painting) to reveal patterns of interspecific chromosomal orthologies across several notothenioid clades.

Results: We defined orthologous chromosomal segments of reference, termed Structural Units (SUs). SUs were identified in a total of 18 notothenioid species. We demonstrated for the first time that SUs were strongly conserved across every specimen examined, with chromosomal syntenies highlighting a paucity of intrachromosomal macrorearrangements. Multiple independent fusions of these SUs were inferred in the Trematomus species, in contrast to the shared SU fusions in species of the sister lineage Notothenia.

Conclusions: The SU segments were defined units of chromosomal rearrangement in the entire family Nototheiidae, which diverged from the other notothenioid families $20 \mathrm{My}$ ago. Some of the identified chromosomal syntenies within the SUs were even conserved in their closest relatives, the family Eleginopsidae. Comparing the timing of acquisition of the fusions in the closely related genera Notothenia and Trematomus of the nototheniid species family, we conclude that they exhibit distinct chromosomal evolutionary histories, which may be relevant to different speciation scenarios.
\end{abstract}

Keywords: BAC-FISH, Chromosomal painting, Chromosomal rearrangements, Chromosomal structural units, Chromosomal synteny, Nototheniidae, Speciation

\footnotetext{
*Correspondence: juliette.auvinet7138@gmail.com;

dominique.hiquet@sorbonne-universite.fr

'Sorbonne Université, CNRS, Université des Antilles, Evolution Paris Seine -

Institut de Biologie Paris Seine (EPS - IBPS), 75005 Paris, France

Full list of author information is available at the end of the article
}

(c) The Author(s). 2020 Open Access This article is licensed under a Creative Commons Attribution 4.0 International License, which permits use, sharing, adaptation, distribution and reproduction in any medium or format, as long as you give appropriate credit to the original author(s) and the source, provide a link to the Creative Commons licence, and indicate if changes were made. The images or other third party material in this article are included in the article's Creative Commons licence, unless indicated otherwise in a credit line to the material. If material is not included in the article's Creative Commons licence and your intended use is not permitted by statutory regulation or exceeds the permitted use, you will need to obtain permission directly from the copyright holder. To view a copy of this licence, visit http://creativecommons.org/licenses/by/4.0/ The Creative Commons Public Domain Dedication waiver (http://creativecommons.org/publicdomain/zero/1.0/) applies to the data made available in this article, unless otherwise stated in a credit line to the data. 


\section{Background}

During the last 20 million years $(M y)$, several glacialinterglacial cycles caused strong pulsatory environmental changes in the Southern Ocean. Glacial maxima on the Antarctic continental shelf and peri-insular plateau led to habitat disturbance, including iceberg scouring and habitat fragmentation [1-5]. In this cooling and fluctuating environment, the monophyletic "Antarctic clade" of the nototheniid fish (Notothenioidei:Nototheniidae ${ }^{1}$ ) adapted via biochemical and physiological innovations (e.g., evolution of the protective antifreeze glycoproteins or AFGPs [913]). Their diversification involved several rounds of species radiation events $[6,14-18]$, which led to ecological, speciesspecific, and genetic differentiation [16, 19-21]. In some clades, chromosomal changes accompanied lineage diversification [22-25]. Because fixation of chromosomal change can lead to reproductive isolation [26, 27], characterization of these chromosomal repatterning events is an important step toward reconstruction of the evolutionary history of the Antarctic teleosts [13, 20, 28].

Reconstruction of the ancestral vertebrate karyotype ( $n=10,12$ or 17 ) [29-31] led to the $n=24$ or 25 inferred teleost "proto-karyotype," resulting from a complete genomic duplication (TGD for the Teleost Genome Duplication) [29-38] and dated between 316 and $226 M y$ [29, 3942]. Great chromosomal stability has generally been found since the TGD in various teleost fish taxa [25, 43, 44], although some species deviate slightly from $n=24-25$ (including cod, Gadus morhua, $n=23$ [45]; fugu, Takifugu rubripes, $n=22$ [46]; sticklebacks, Gasterosteus aculeatus, $n=21$ and Apeltes quadracus, $n=23$ [47, 48]; and tetraodon, Tetraodon nigroviridis, $n=21$ [49]).

The "proto-karyotype" of $n=24$ acrocentrics has been hypothesized to be the plesiomorphic state for the notothenioid sub-order $[50,51]$, because $n=24$ is found in the families Bovichtidae $[50,52]$, Pseudaphritidae, and Eleginopsidae $[52,53]$, the latter being the closest taxon to the Nototheniidae. Many sub-families of the mostly Antarctic endemic family Nototheniidae have quite conserved karyotypes (Channichthyinae: $n=24$ [22, 54], Artedidraconinae: $n=23[24,55,56])$, whereas other sub-families display high variability in chromosome numbers. The most striking chromosomal diversity has been found within the genus Trematomus of the subfamily Trematominae [23, 24, 57], in which haploid chromosome numbers range from 29 to 12 [51, 57]. Besides, species in the genus Notothenia of the Nototheniinae, have also experienced massive chromosomal reductions in karyotypes $(n=11,12$ and 13) [22, 24, 25].

\footnotetext{
${ }^{1}$ Throughout this publication we use the notothenioid nomenclature of Duhamel et al. [6], which designates the "Antarctic clade" as the family Nototheniidae, including 11 subfamilies (Fig. 7). This clade is synonymous with the AFGP-bearing notothenioids of Matschiner et al. [16] and the Cryonothenioidea of Near et al. [17].
}

Karyotypic variability in the Nototheniidae has also been documented within single species in these genera [22$24,57,58]$. Pericentric inversions, fusions and fissions of chromosomes and chromosomal segments, mediated by mobilization of retrotransposons [59, 60], have been hypothesized to be the most common causes of chromosomal diversification in Trematomus and Notothenia $[22,23,51,61]$. Thus, genomic rearrangements, which are known to result in post-zygotic gametic incompatibilities, may have accompanied speciation events within the Nototheniidae [27, 62-65].

To identify chromosome rearrangement events occurring during nototheniid diversification, interspecific chromosomal homologies (ICHs) must be characterized. To overcome the difficulties in correctly comparing sizes and morphologies among nototheniid chromosomes, we determined a chromosomal unit of reference called a Structural Unit (SU) based on the karyotype of the platyfish, Xiphophorus maculatus, and transposed via synteny to the karyotype of the three-spine stickleback, G. aculeatus, and the Antarctic bulhead notothen, Notothenia coriiceps by [25]). SUs of Notothenia and Trematomus species were then identified by Fluorescence In Situ Hybridization (FISH) of BAC-clones containing genomic DNA of $N$. coriiceps [6668] and by chromosomal painting. Results show that chromosomal fusions in Trematomus occurred independently in different species lineages, unlike the mostly shared fusions of Notothenia species, highlighting contrasting evolutionary histories between genera within the Nototheniidae.

\section{Results}

Broad conservation of structural units (SUs) across notothenioid clades

Identifying SU markers: hybridization of N.coriiceps BACs to N. coriiceps chromosomes

Our first goal was to develop BAC-FISH probes for the teleost SUs defined in Amores et al. [25]) based on comparative genetic mapping of the genomes and karyotypes of $X$. maculatus, G. aculeatus, and $N$. coriiceps. We selected $40 N$. coriiceps BACs at random and screened 37 by hybridization to chromosome preparations of $N$. coriiceps. The remaining three were hybridized only on Trematomus species chromosomes. Results revealed three main types of fluorescent signals (Additional file 1). Twenty-two BACs (55\% of total), including 19 BACs in $N$. coriiceps, gave clearly discrete double spots at a single location on one chromosomal pair ("specific" signals; Fig. 1a), corresponding to specific hybridization to unique chromosomal sequences. The second pattern involved broader bands detected on multiple chromosome pairs and usually in centromeric/pericentromeric regions ("repetitive", Fig. 1b) and was found for seven BACs (17.5\%). These multiple hybridization signals were probably due to high proportions 

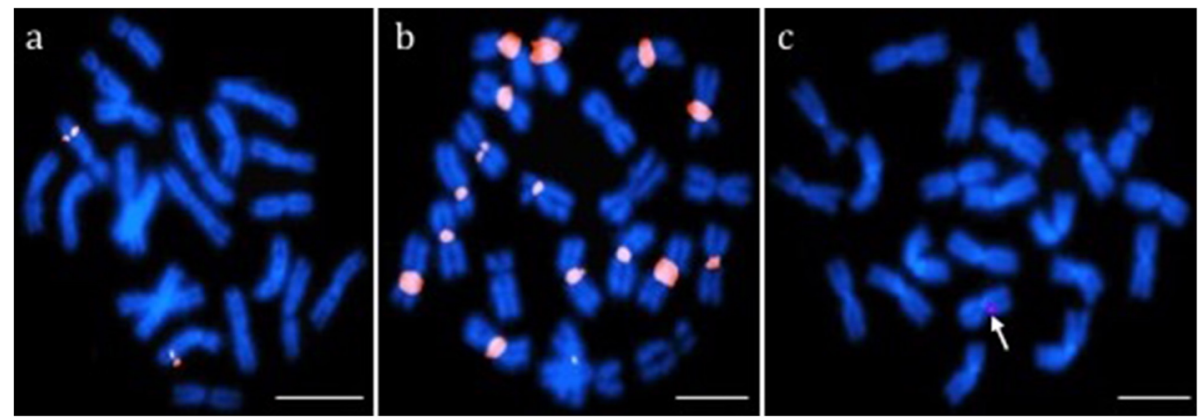

Fig. 1 BAC hybridization signals on chromosomes of N. coriiceps. a Specific signal: Strong, discrete signal on a single chromosome pair (example with BAC M11). b Repetitive signal: Repetitive, typically centromeric/pericentromeric signal on multiple chromosome pairs (example with BAC B9). c Weak signal: Weak signal, rarely detected on chromosomes (example with BAC • J2). Only BAC probes producing specific signals were used for subsequent analyses. Hybridization patterns were independent of the fluorochrome used for detection. Scale bars: $10 \mu \mathrm{m}$

of repetitive sequences (e.g., transposable elements, satellites, etc.) that were not blocked despite prehybridization with competitor and carrier DNAs. The third signal category ("weak" signals; $11 \mathrm{BACs}=27.5 \%$ ) presented as weak spots (single or multiple) in nuclei that were rarely visible on metaphasic chromosomes (Fig. 1c). These weak signals could be due to genomic content of the BAC itself, or to defective probe labeling. Only the 22 BACs that produced the specific signals were selected for subsequent chromosomal analyses (Fig. 2).

\section{Conservation of structural units across nototheniid species}

To test whether genetic synteny is conserved between the SUs defined for $N$. coriiceps and the chromosome sets of other notothenioid species, we hybridized BACs in various combinations to chromosome preparations from species representing the Trematominae, Dissostichinae, Channichthyinae, Cygnodraconinae and Gymnodraconinae. First, we used two or more SU-specific BACs to evaluate marker positions and orientations relative to centromeres and telomeres and to evaluate inter-marker distances. Fig. 2 shows that five distinct SUs in $N$. coriiceps are defined by multiple BACs: three by two BACs (K19/D2, M11/85H3, F5/E21, respectively), one by three BACs (F15/H12/C4), and one by four BACs (28D21/G6/25G6/•F8).

To determine the extent to which SUs are conserved in nototheniids, we hybridized the BAC pair C4 and F15 (chosen randomly among the BAC pairs that delineated a single SU in N. coriiceps; Fig. 2) to eight species of Trematomus (Fig. 3a, Additional file 1) and eight other notothenioid species (Fig. 3b, Additional file 1). Results showed that the relative positions of the two markers mapped to single chromosome arms of all species and that the distances between them were generally well conserved. Thus, C4 and F15 define an orthologous SU across the 16 species, which include two Sub-Antarctic species (E. maclovinus, $P$. ramsayi). Furthermore, BACs 28D21, C4, and M11 consistently labeled near pericentromeric regions, whereas BACs E21 and 85H3 were found near telomeric regions of their respective SUs (Fig. 2). However, labeling by BAC 44 M14 was variable, being found in the middle of a SU of $N$. coriiceps (Fig. 2) and T. pennellii (Fig. 4), but in pericentromeric regions of a SU in T. bernacchii, T. hansoni, T. newnesi, and T. eulepidotus (Fig. 4). Such changes in

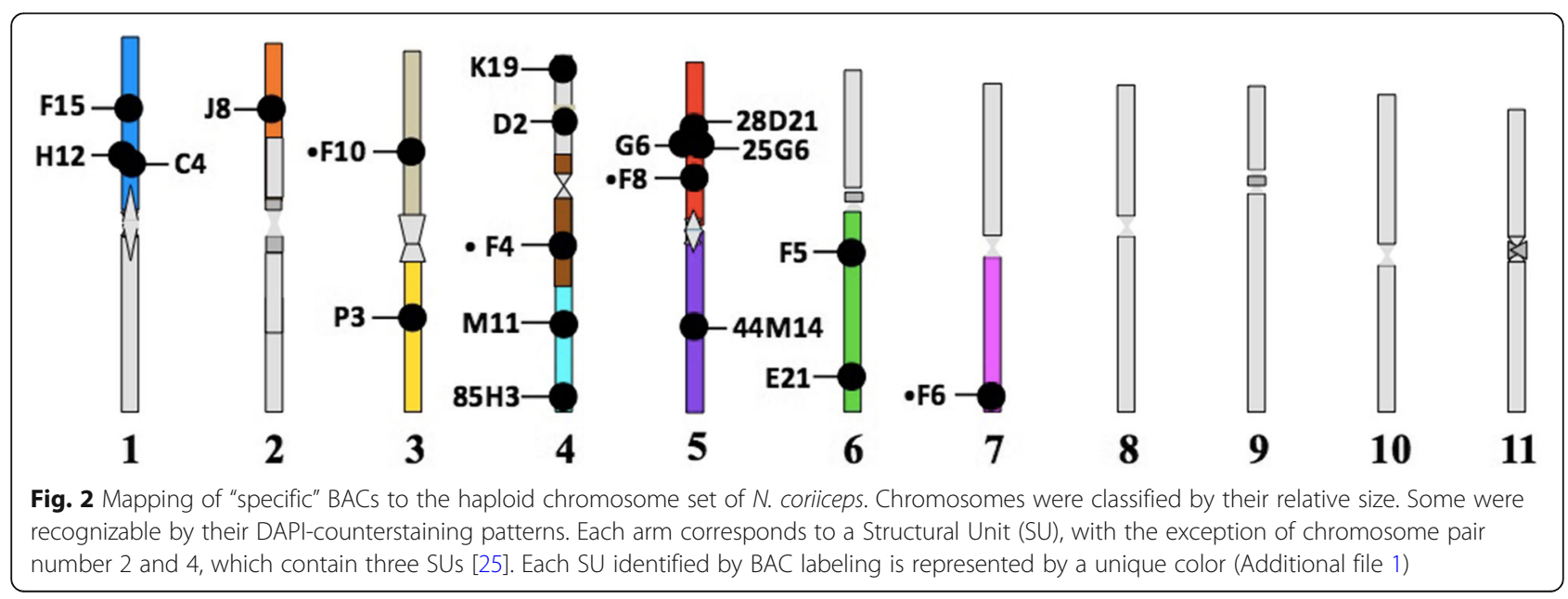



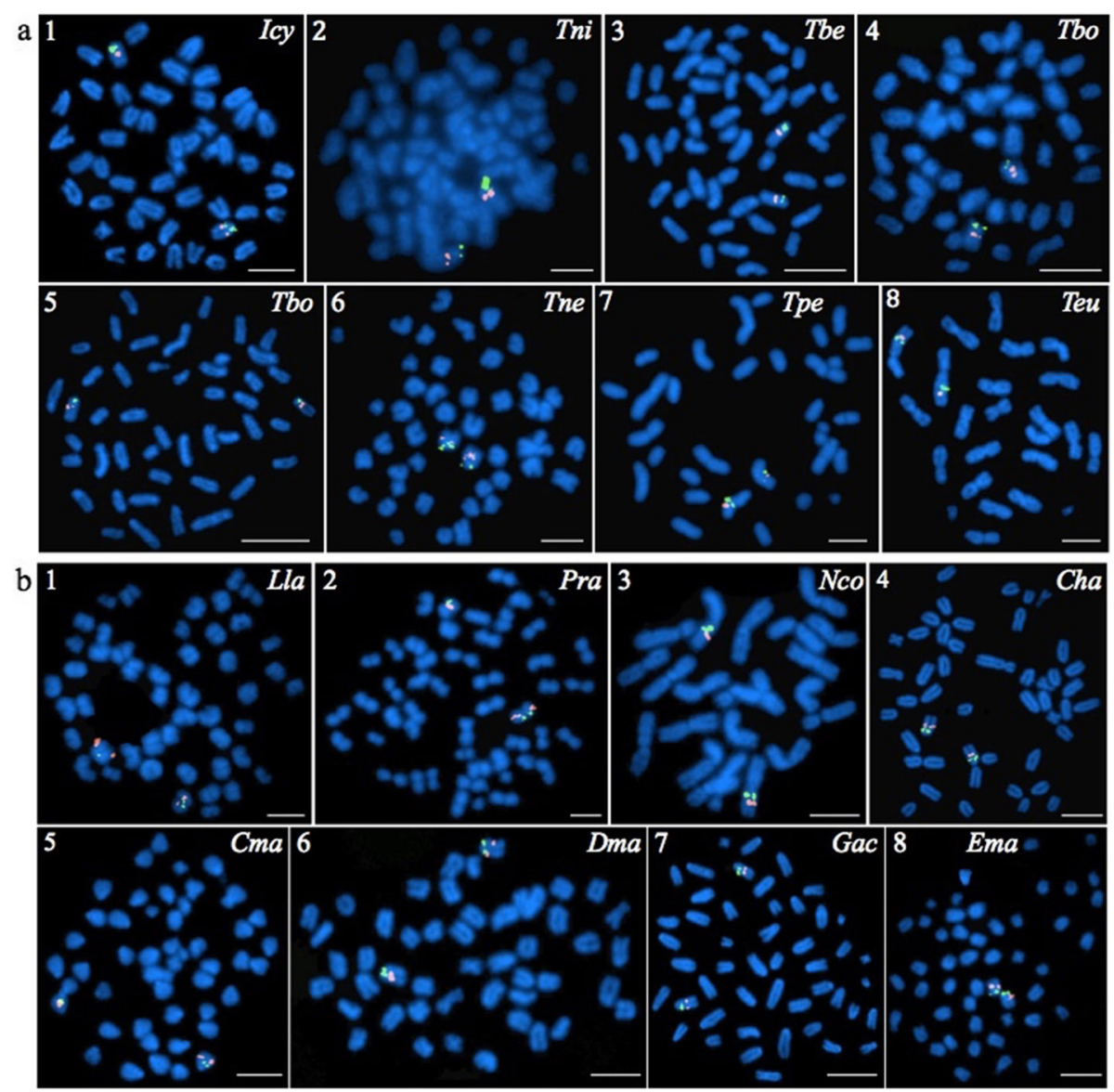

Fig. 3 Hybridization of BACS C4 and F15 defines a conserved SU in the Trematominae and other notothenioid clades. a) Trematomus species: 1, I. cyanobrancha (Icy); 2, T. nicolai (Tni); 3, T. bernacchii (Tbe); 4, T. borchgrevinki (Tbo); 5, T. hansoni (Tha); 6, T. newnesi (Tne); 7, T. pennellii (Tpe); and 8, T. eulepidotus (Teu). b) Eight notothenioid species from other clades: 1, L. larseni (Lla); 2, P. ramsayi (Pra); 3, N. coriiceps (Nco); 4, C. hamatus (Cha); 5, C. mawsoni (Cma); 6, D. mawsoni (Dma); 7, G. acuticeps (Gac); and 8, E. maclovinus (Ema). Hybridization of BAC C4 probe was detected using fluorescein (green signals), whereas BAC F15 was imaged using rhodamine (red signals). Chromosomal DNA was counterstained with DAPI (blue). Scale bars: $10 \mu \mathrm{m}$

location with respect to the centromere could be explained by either pericentric or paracentric inversions.

The relative distances between BAC hybridization locations were also conserved across species, again exemplified by centromeric BAC C4 and interstitial BAC F15 (Figs. 3 and 4). Similarly, pericentromeric BAC F5 and subtelomeric BAC E21 were located in the same SU and separated by equivalent distances in the eight Trematomus species (Fig. 4).

Recognizing the high degree of interspecific conservation of chromosomal synteny among the notothenioids $[25,69]$, we also used six BACs that hybridized as singletons to $N$. coriiceps SUs (Fig. 2) to infer SUs in other species. In these cases, we explicitly assume that a single $\mathrm{BAC}$ signal indicates the conservation of an entire SU, at least at the chromosomal scale (macro-rearrangements). Conserved synteny could even be extrapolated to the whole SU for cases we studied. Six additional SUs were labeled by a unique $\mathrm{BAC}$ in species of the genus
Trematomus (Fig. 4), and two additional SUs in species of the genus Notothenia (Fig. 5).

\section{Chromosome fusions in the Nototheniidae: independent events in Trematomus, shared events in Notothenia}

The Nototheniidae are notable for their diverse karyotypes, with both fusions and fissions altering the canonical teleost chromosome set of $n=24$ [50,51]. Regarding fusions, for which we have the most data in the genera Trematomus and the Notothenia (Figs. 2, 3, 4, 5), one may ask: did they occur independently among the species of these clades? Or are they shared by virtue of descent from a common ancestor? Surprisingly, the answer appears to be taxon-specific. Results showed that an overwhelming majority of the centric and/or tandem fusions detected in this study were not shared among Trematomus species (Fig. 4). For example, the largest submetacentric pairs of T. pennellii and T. eulepidotus, each of which probably arose by a combination of centric and 


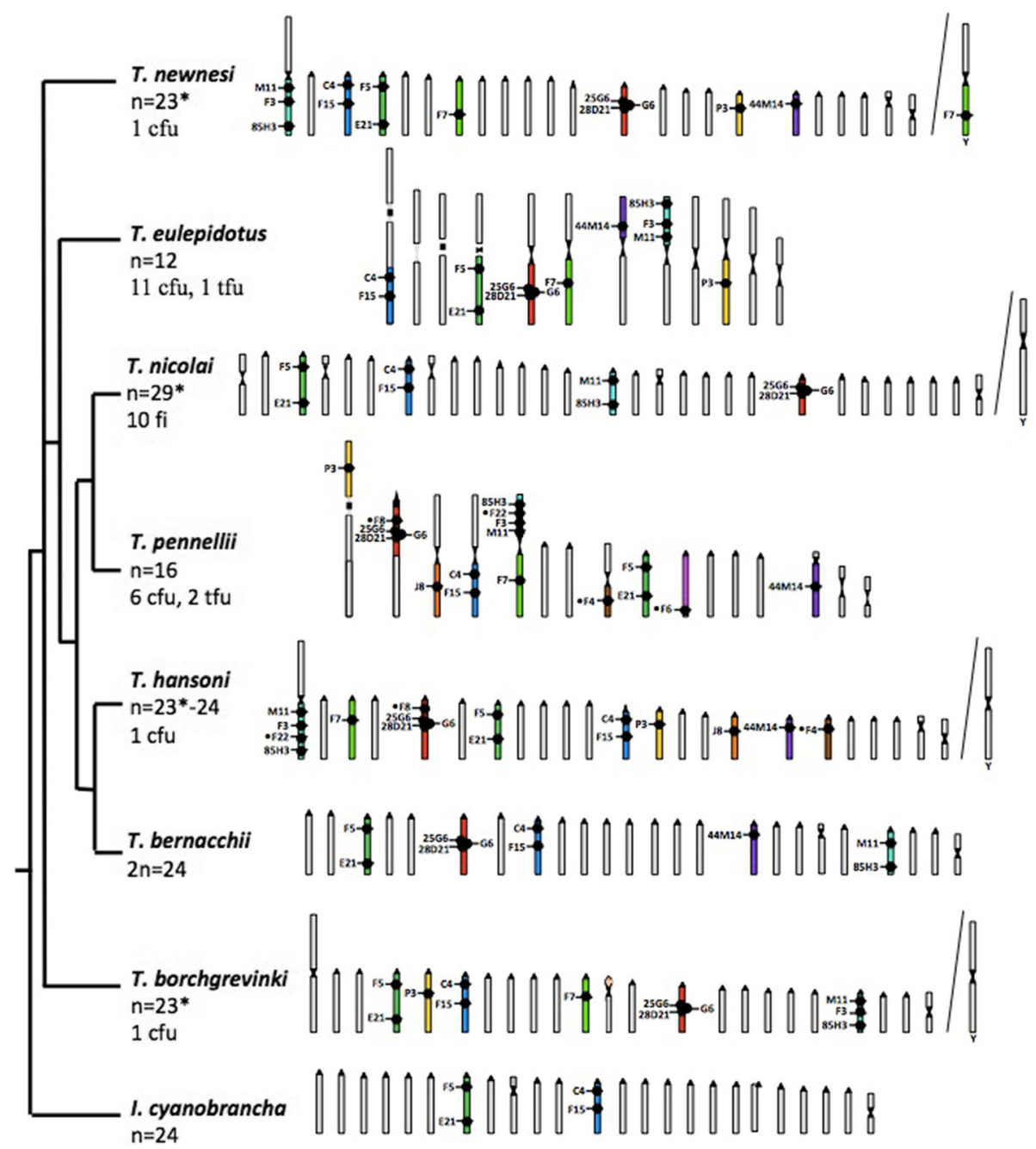

Fig. 4 Mapping of BAC-defined SUs onto the idiograms of haploid female chromosome sets of eight Trematomus species. Karyotypes with identified SUs and fusions are plotted against the Trematomus phylogeny [8]. Orthologous SUs are shown in the same color. Four species (T. nicolaï, T. hansoni, T. borchgrevinki and T. newnesi) have sex-differentiated chromosomes (X1X1X2X2 (female) / X1YX2 (male)). The haploid female chromosome number of each is presented, while asterisks indicate when male (chromosomal formulae: $2 n-1)$, and the male chromosome ( $Y$ ) is shown on the right side of the corresponding karyotype. Total numbers of fusions (cfu, centric fusion; tfu, tandem fusion) or fissions (fi) are indicated (based on female karyotypes) for the six species that deviate from $n=24$. Specific BAC designations are given next to their locations on chromosomes. Note that BACS F3, F7 and •F22 were not mapped to N. coriiceps SUs in Fig. 2

tandem fusion events [27], contained non-orthologous SUs (orange and blue, respectively; Figs. 4, 5a). The red SU (defined by BACs 28D21, 25G6, G6 and •F8) was fused tandemly in $T$. pennellii but formed a centric fusion in $T$. eulepidotus (Figs. 4, 5a). The green and purple SUs (marked by BACs F7 and 44 M14, respectively) partnered in a centric fusion in T. pennellii, whereas they were involved in centric fusions with different SUs in T. hansoni, T. newnesi and T. eulepidotus (Fig. 5a). We conclude that many, if not all, of the chromosomal fusion events in the Trematomus radiation occurred independently.

Throughout the trematomine species examined, the SUs defined by BACs $28 \mathrm{D} 21$ and $44 \mathrm{M} 14$ were found in two different chromosomes. In striking contrast, these SUs were fused centrically to form the same orthologous metacentric chromosome pair in the three species of the genus Notothenia (Fig. 5b), as shown by the relative positions of the BACs on their SUs. Our observation supports prior results obtained by genetic mapping [25], that demonstrate that chromosomal fusions in this genus are generally shared across the three species.

\section{Identification of nototheniid interspecific chromosomal homologies (ICHs) by chromosomal painting}

We hypothesize that the uniquely identifiable largest submetacentric pair of T. pennellii arose by the fusion of several SUs. To test that hypothesis, we used a painting probe prepared from $T$. pennellii chromosome 1 to search for 


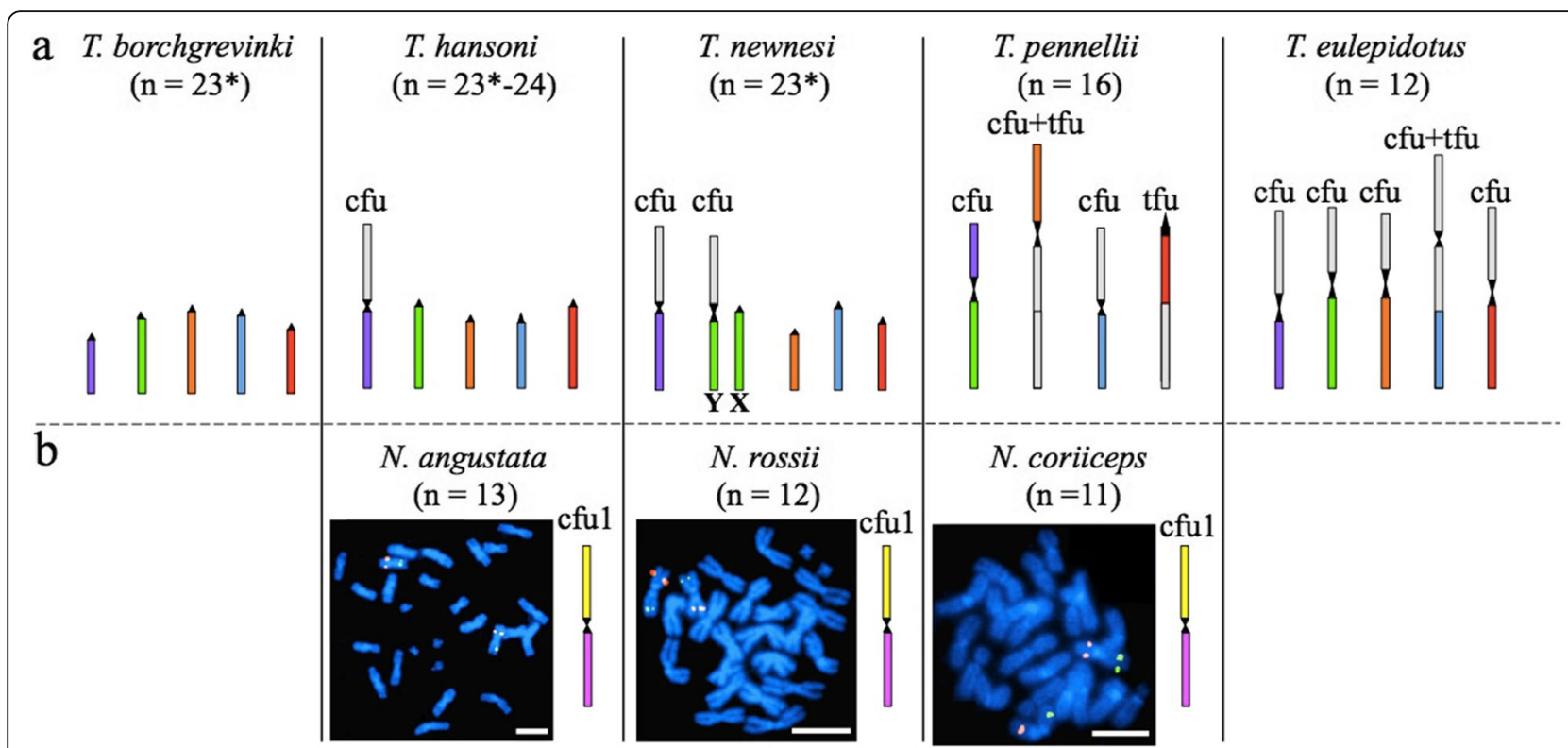

Fig. 5 Comparison of chromosomal fusions in the genera Trematomus and Notothenia. A subset of BAC-defined SUs was used to characterize chromosomal fusion (cfu: centric fusions, tfu: tandem fusion). Each distinct SU is represented by a unique color. Orthologous SUs are labeled by the same color. a Trematomus species. Independent chromosomal fusions were observed in the five species shown. The asterisks indicate when male (chromosomal formulae: $2 \mathrm{n}-1$ ). The green SU was found in the heteromorphic $\mathrm{Y}$ sex chromosome in males in T. newnesi, which corresponds to the X1 or X2 sex chromosome in females. T. borchgrevinki and T. hansoni were represented only by females in this study (Additional file 2). b Notothenia species. BAC pair 28D21 (green signal) and 44 M14 (red signal), which label different SUs (Additional file 1), revealed that orthologous SUs formed the same metacentric pair in the three Notothenia species (cfu1 = shared fusion). Abbreviations: cfu; centric fusion; tfu, tandem fusion. Scale bars: $10 \mu m$

interspecific chromosomal homologies in other notothenioid species. Hybridization of the T. pennellii probe to chromosome spreads from T. pennellii gave the expected robust, full-length hybridization to chromosome pair 1 (Fig. 6a). In addition, chromosome pair 2, the second largest and acrocentric chromosome, showed intense and uniform hybridization near the centromere and some punctate staining elsewhere. Other chromosome pairs were characterized by weak staining of small, often telomeric regions. These nonspecific signals probably correspond to repetitive elements present in the probe, such as DIRS1 retrotransposons [59].

Interspecific hybridization of the T. pennellii chromosome 1 painting probe to chromosomes of $T$. hansoni and D. mawsoni labeled three small acrocentric pairs in both species (Figs. 6b, c): 3, 9 and 13 for the former, and 9, 10, and 11 for the latter. Therefore, chromosome pair 1 of $T$. pennellii results from a centric and a tandem fusion involving three SUs (Figs. 4 and 5) inherited from the most recent common ancestor of the Nototheniidae. Nonspecific low level signals like those observed in T. pennellii were also dispersed on other chromosomes.

\section{Discussion}

\section{Sequence conservation in notothenioid fish}

Within the suborder Notothenioidei, the family Nototheniidae is both the most speciose $[6,7,19,28]$ and the most prone to chromosomal rearrangements [24, 57, 61]. The specific hybridization of 22 of 40 randomly selected BACs from $N$. coriiceps to 18 representatives within the Nototheniidae suggests, as anticipated, strong sequence conservation within the family. This finding is consistent with the recent divergence time of the family, dated between 22.4 and 13.35 My [14, 10] (Fig. 7). Strong conservation across nototheniid genera has already been mentioned for the comparison of $N$. coriiceps and $C$. aceratus [66, 67], and in molecular phylogenetic studies conducted in the whole family [14-17]. We also demonstrated that this conservation can be extended to the sister family of Nototheniidae, the Eleginopsidae, which diverged between 42 and $37 M y$ [14, 17] (Fig. 7). We did not detect hybridization of two N.coriiceps BACs, C4 and F15, to Bovichtus diacanthus from the more distantly related family Bovichtidae (divergence time between 78 and $65 M y$ [14, 17] (Fig. 7)).

\section{Chromosome rearrangement units in Nototheniidae}

Strong interspecific conservation of chromosomal segments was identified through BAC combinations that colocalized in the same SU (Figs. 3 and 4). Based on these observations of BAC positions as well as on the chromosomal painting results, the SUs defined in [25] could indeed be the primary units for most rearrangements that occurred during nototheniid species diversification. Those chromosomal units are shared and conserved across nototheniid 

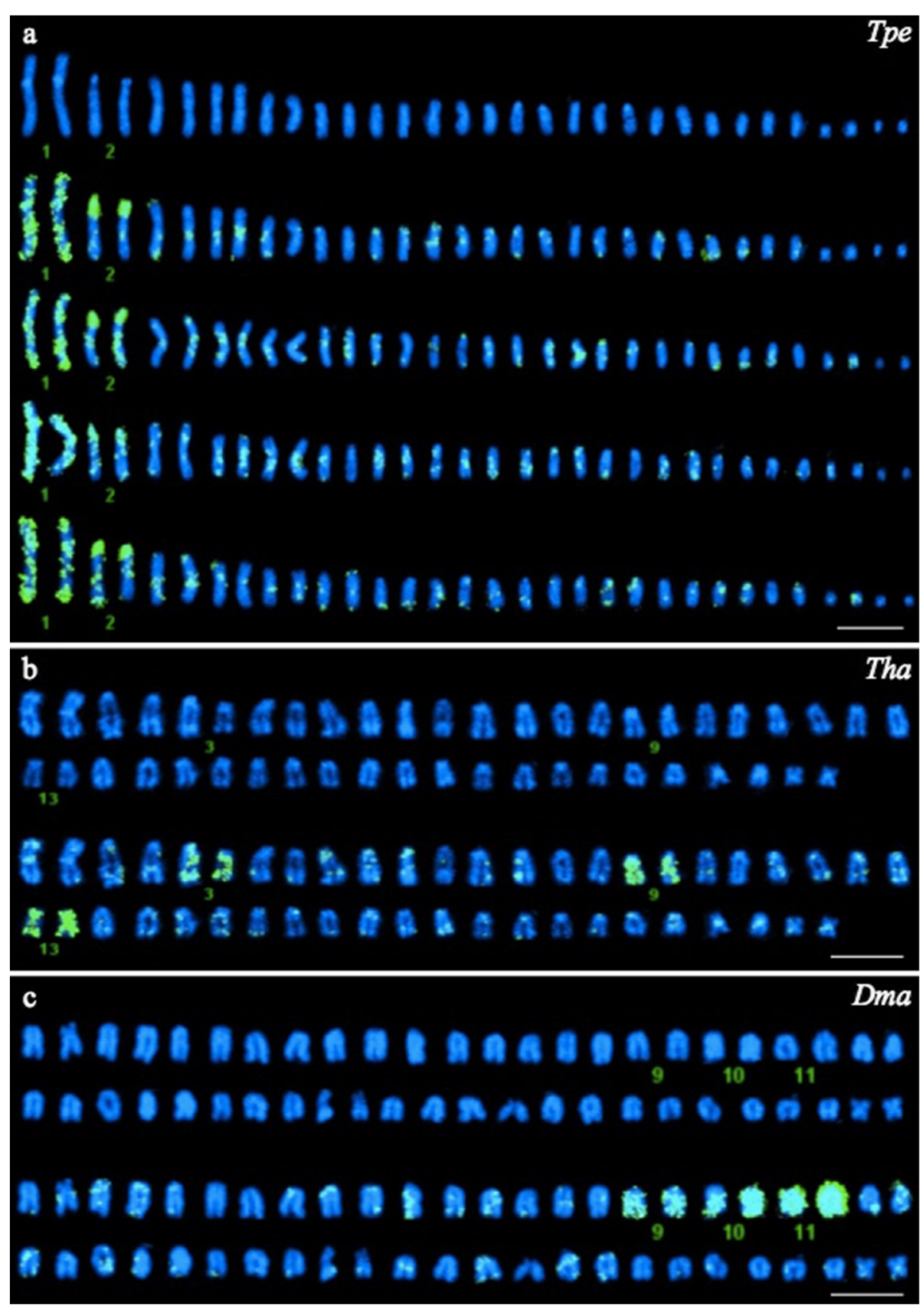

Fig. 6 Chromosome 1 of T. pennellii is a fusion product of three ancestral chromosomes. a Positive control: Hybridization of the T. pennellii painting probe to $T$. pennellii chromosomes $(n=16)$. $\mathbf{b}$ and $\mathbf{c}$ Hybridization of the T. pennellii probe to chromosomes from T. hansoni (Tha, $n=23$ ) and from D. mawsoni $(n=24)$, respectively. Each panel shows a DAPI-stained karyotype at the top, and one $(b, c)$ or more (a) karyotypes after hybridization of the painting probe. Bound painting probe was imaged by FISH, and detected using fluorescein (green signals). Numbered chromosome pairs are referenced in the text. Scale bars: $10 \mu \mathrm{m}$

genera. The SUs would thus have probably been inherited from the last common ancestor of the Nototheniidae (Fig. 7) $[23,24,51,57]$. This interspecific conservation goes hand in hand with a low number of macro-rearrangements detected within a SU. We did not observe any chromosomal inversion or translocation/transpositions at the SU scale when locating the BACs and identifying ICHs, although the pericentromeric vs interstitial positions of BAC 44 M14 revealed the possibility of local and segmental insertions/deletions (Figs. 2 and 4). This hypothesis is also supported by our painting results (one chromosome of $T$. pennellii corresponds to three acrocentrics in T. hansoni and D. mawsoni) and corroborated by the absence or low number of secondary 


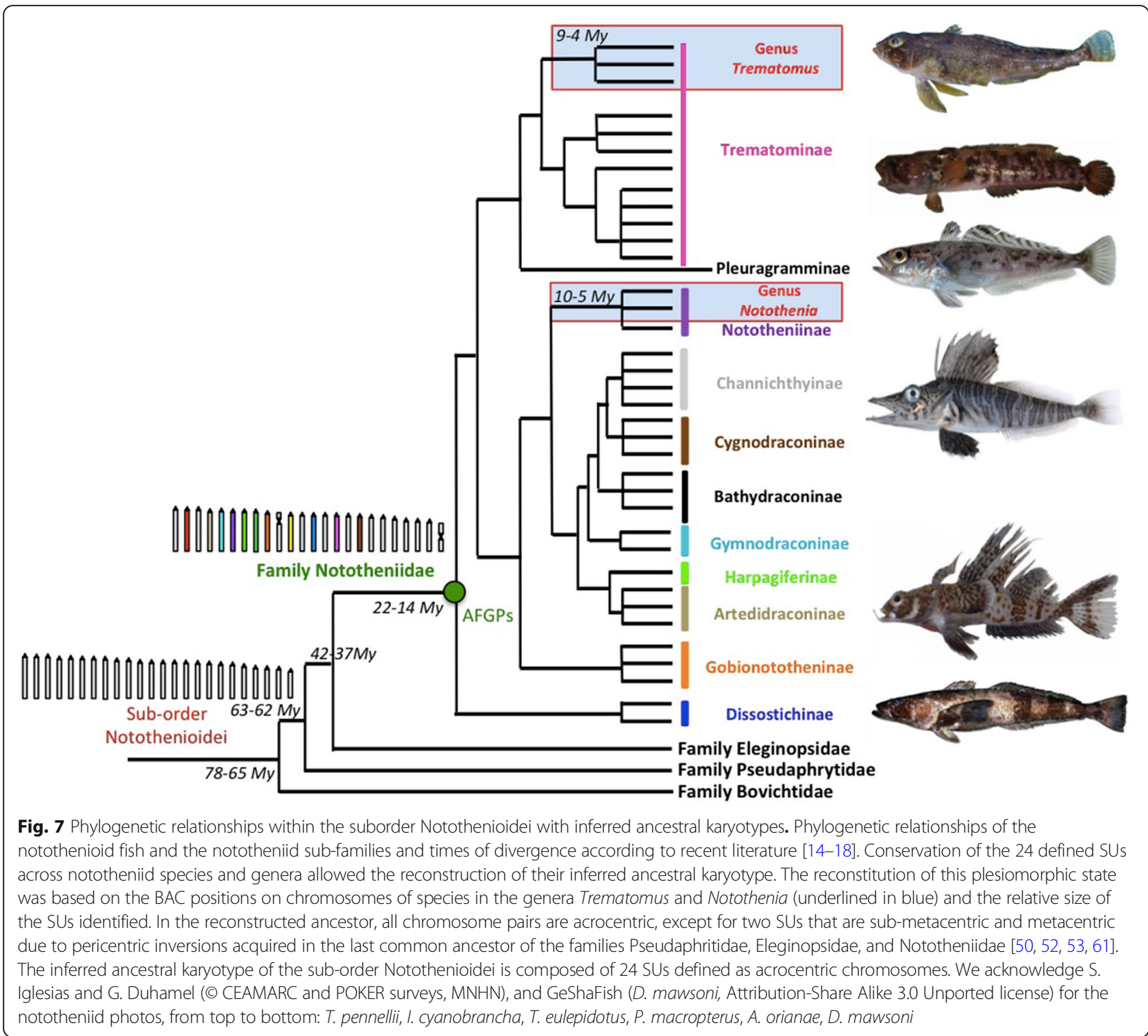

rearrangements, as suggested for the genus Notothenia by Amores et al. [25].

The various ways in which these SUs are rearranged in the different species generated the karyotype diversity currently observed in this group. This study confirmed the previously hypothesized importance of structural fusions accompanying speciation events, including constant genome size despite changes in chromosome number $[23,51,59,61$, 66]. Based on a comparison of the total number of chromosomes in nototheniid species, some authors hypothesized a tendency to chromosome number reduction by fusions [23, $51,55,57,61]$. The use of BACs to identify orthologous chromosomes in the genera Trematomus and Notothenia, coupled with observations on chromosome morphology and relative sizes, confirm that chromosome fusions (either Robertsonian fusions or tandem fusions) are the major type of macro-rearrangement event that occurred during chromosomal evolution in this family $[23,25,51,57,61]$.

\section{Shared or independent fusions: two contrasting evolutionary histories of karyotype diversification} Comparing the locations of selected BACs in the different nototheniid species enabled us to reconstruct the evolutionary scenario of the fusions that accompanied the diversification of the genera Trematomus and Notothenia. Because the centric or tandem fusions detected in the present study in the different Trematomus species did not involve the same SUs, they resulted from events occurring independently in the different lineages. ICH (interspecific chromosomal homologies) characterization, however, is needed to generalize these observations to all fusions detected in the Trematomus karyotypes (Fig. 4). Indeed, if 
we assume that the fusion involving the purple and the green SUs is specific to T. pennelli, then, we still need to identify the SU(s) fused to the purple SU in T. hansoni, $T$. newnesi and T. eulepidotus to determine whether the corresponding chromosomes are homologous in these species (Figs. 4 and 5).

The evolutionary pattern of karyotype evolution in the genus Notothenia completely differed from that of the genus Trematomus. Cytogenetic labeling identified one centric fusion (cful in Fig. 5b) shared across the three closely related Notothenia species: $N$. coriiceps, $N$. rossii and $N$. angustata $[14,16,17,70]$. This observation corroborates the evolutionary scenario proposed by Amores et al. [25]) of at least eleven chromosomal fusions acquired in the last common ancestor of Notothenia (including also P. magellanica). Furthermore, the SUs that fused to form the chromosome pair highlighted in Fig. 5 for Notothenia species were never associated together in the Trematomus species we examined ( $T$. eulepidotus, T. pennellii, T. newnesi and T. bernacchii) (Fig. 4). Therefore, this centric fusion (cfu1 in Fig. 5) is probably not shared between the Trematomus and Notothenia species.

We could not determine whether all of the chromosome fusions in various Notothenia species resulted from a common history. Markers for more SUs would be required to investigate whether every metacentric or submetacentric in N. coriiceps (for example, $\cdot F 10$ and P3, or D2 and •F4, Fig. 1) fused with the same partner in other Notothenia species. If all fusions were shared across the genus, then the fusion events would have happened at the base of the Notothenia diversification before species divergence. It is also possible that additional events occurred after the speciations, such as the translocation between a segment containing the NOR genes in the middle of a sub-metacentric pair in P. magellanica and a small acrocentric pair in $N$. angustata (both $n=13$ ). Alternatively, some of the fusions could have been acquired independently in some lineages (like one or two sub-metacentric pairs of $N$. rossii $(n=12)$ or $N$. coriiceps $(n=11)$ respectively thought to combine three fused SUs [25]).

\section{"Chromosomal speciation"?}

The fixation of chromosomal fusions in populations constitutes a step toward reproductive isolation [26, 27] because during meiosis the fused chromosome from one population would pair with the two ancestral unfused chromosomes from the other population, leading to the production of aneuploid gametes, to aneuploidy offspring, and presumably to non-viable hybrid progeny. Because they promote the accumulation of genetic incompatibilities, chromosomal fusions may have facilitated lineage-specific diversification in rodents, insects, and also in fishes [71-78]. As proposed previously in the literature, chromosome fusions are the major rearrangement events accompanying nototheniid species diversification, although pericentric inversions and chromosome fissions have also occurred [23, 50-53, 57, 58].

Identifying interspecific chromosomal orthologies in the highly rearranged karyotypes of species in the genus Trematomus demonstrated that chromosomal fusions were mostly acquired independently across lineages. We characterized numerous fusions, but none so far were shared in this group, when taking into account the phylogenetic relationships across the different species (Fig. 4), although previous studies hypothesized the sharing of other type of rearrangements [24, 26, 50, 53]. Indeed, the two shared pericentric inversions acquired before the last common ancestor of the Pseudaphritidae, Eleginopsidae, and Nototheniidae families may have produced the chromosomal pair bearing the $5 \mathrm{~S}, 18 \mathrm{~S}$ and $28 \mathrm{~S}$ ribosomal genes, and the smallest metacentric pair not labeled by our BACs (Figs. 4 and 7) [22, 24, 61]. In contrast, Notothenia species would mostly share fusions, characteristic of their reduced chromosomal number [25]. However, some fusions in N. rossii and in N. coriiceps could have appeared independently, as hinted by the different positions of the ribosomal genes either in a long arm, or in a short arm of sub-metacentric, probably non orthologous pairs [54, 79].

Positioning chromosomal fusions relative to speciation events is not easy for the Trematomus group given the multiple acquisition of rearrangement events and difficulties in establishing a reliable phylogeny for this radiation $[15,80]$. Bursts of retrotransposon mobilization (including the DIRS1 elements) possibly associated with environmental stress of the glaciation and deglaciation cycles on the Antarctic continental shelf have been proposed as a cause of genomic plasticity, facilitating chromosomal diversification $[59,60]$. During mobilization of retrotransposons, DNA breaks and recombination may have occurred in different genomic locations, and thus involved different SUs and fusions in distinct populations. The process of speciation can last millions of years before two populations become completely isolated reproductively. Either ancestral or recent karyotypic polymorphisms are possible when taking into account the history and ecological context of the Trematomus adaptive radiation. Both alternatives would involve multiple independent fusions, and reinforce species isolation. Those fusions would then be randomly fixed in each of those diverging populations. In contrast, in the Notothenia group, fusions would mostly have been acquired before the Notothenia/Paranotothenia divergence (10-5 My, [14, 17] (Fig. 6). Indeed, the timing of diversification differs between the Notothenia and Trematomus groups. In contrast to the rapid diversification of genus Trematomus $[15,16$, 80], the Nototheniinae is not considered as a radiation [7, $14,19,20,70]$. Fusions in the Nototheniinae might have had much more time to arise and become fixed in different populations before the next species divergence. 
Even though Trematomus and Notothenia show two distinct and specific histories of fusion acquisition, the system may not be completely binary: in both groups, some fusions might have occurred early and some later. Further, largescale studies would be needed to establish the timing of retrotransposon bursts and to identify and characterize rearrangement events in the different nototheniid groups to better understand these evolutionary histories and their link to speciation.

\section{Conclusions}

We identified for the first time a large number of specific genomic regions involved in specific fusion event. We showed that large acrocentric, metacentric or submetacentric mitotic chromosomal pairs are indeed mostly products of chromosome fusions, which are the most frequent type of rearrangement event in the Nototheniidae $[23,57,61]$. We also demonstrated that the chromosomal segments (SUs) are strongly conserved across all notothenioids examined. Fusions involving multiple SUs that we examined are independent within the genus Trematomus, whereas they are shared among Notothenia species, illustrating two contrasting evolutionary histories of karyotype diversification within the family. These fusions may have accompanied the establishment of reproductive barriers between populations, or might have merely reinforced barriers initiated by other mechanisms. In either case, chromosomal fusions would be important actors in nototheniid speciation.

The increasing availability of nototheniid genome sequences and improved genome assemblies will enable the use of in silico genomic approaches to supplement cytogenomic tools for a comparative and integrated perspective, although experiments such as the ones described in this study are required to link genomics to physical chromosomes. Genome sequencing and assembly will improve both the resolution of chromosomal syntenies and the possibility to detect various types of chromosomal microrearrangements.

Divergence among nototheniid species is quite recent, so the chromosomal syntenies are highly conserved at the family scale. Even though the Southern Ocean is currently a highly stable environment, predicted perturbations including warming of about $0.1^{\circ} \mathrm{C}$ per decade [8184] are likely to have dramatic consequences on species evolution and development, with possible impacts on genome architecture and plasticity, and could deeply accelerate genomic changes and restructuring.

\section{Methods}

\section{Fish specimens}

Specimens of nineteen notothenioid species (Bovichtus diacanthus, Chionodraco hamatus, Cygnodraco mawsoni, Dissostichus mawsoni, Eleginops maclovinus, Indonotothenia cyanobrancha, Gymnodraco acuticeps, Lepidonotothen larseni, Notothenia angustata, Notothenia coriiceps, Notothenia rossii, Patagonotothen ramsayi, Trematomus bernacchii, Trematomus borchgrevinki, Trematomus eulepidotus, Trematomus hansoni, Trematomus newnesi, Trematomus nicolai, Trematomus pennellii) were collected during the French, Italian and American demersal fish survey programs. The chromosomal preparations and tissue samples for DNA extraction used are listed in Additional file 2.

\section{Chromosomal preparations}

Mitotic chromosome preparations were obtained from primary cell cultures of pronephric kidney or spleen strictly following the specific protocol for Antarctic fish described in Rey et al. [85]. Fixed cell suspensions were preserved as aliquots of $15 \mathrm{ml}$ at $-20^{\circ} \mathrm{C}$. Prior to use, suspensions were thawed and centrifuged at $1500 \mathrm{rpm}$ (Centrifuge 5424R, Eppendorf, Hamburg, Germany) for $10 \mathrm{~min}$ at $4{ }^{\circ} \mathrm{C}$. After removing supernatants, cell pellets were resuspended in $0.8-1 \mathrm{ml}$ of fresh fixative $(3: 1 \mathrm{mix}$ of cold ethanol/glacial acetic acid), and were spread onto Superfrost slides (precleaned with absolute ethanol containing $1 \%$ of $1 \mathrm{~N} \mathrm{HCl}$ ) for BAC-FISH and chromosomal painting. For microdissection, cell suspensions were spread onto $40 \times 60 \mathrm{~mm}$ coverslips and stained with GIEMSA (4\%) for $12 \mathrm{~min}$. Slides were stored at $-20{ }^{\circ} \mathrm{C}$ until further use. Additional file 2 summarizes the chromosomal preparations used in this study.

\section{Probes preparation \\ $B A C$ probe selection}

BAC clones used in this study were isolated from the Notothenia coriiceps VMRC-19 BAC library (average insert size $138 \mathrm{~kb}$ ) [66-68]. Forty BACs were randomly selected from two 384-well plates (number 25 and 58). Four BACs (named 28D21, 25G6, 85H3, and 44 M14) were partially sequenced to determine their gene contents. The remaining 36 clones were not sequenced. The latter were named from their plate coordinates (with a • to differentiate the BACs extracted in plate number 58).

\section{$B A C$ amplification}

BAC clones (138 kb average insert size) were amplified to provide genomic DNA for the BAC-FISH probes. For each BAC, $5 \mu$ l of its glycerol stock were inoculated into $5 \mathrm{ml}$ of Lysogeny Broth (LB) culture medium containing chloramphenicol $(12.5 \mu \mathrm{g} / \mathrm{ml})$, and the mini-culture was incubated for $5 \mathrm{~h}$ at $37^{\circ} \mathrm{C}$ with agitation $(200 \mathrm{rpm}$, Incubating Orbital Shaker 12,620-946, VWR, Radnor, PA, USA). The culture was then transferred to $95 \mathrm{ml}$ of enriched LB culture medium, and the midi-cultures were incubated for $18 \mathrm{~h}$ at $37^{\circ} \mathrm{C}$ with agitation (200 rpm, Incubating Orbital Shaker 12,620-946, VWR). Once a culture attained an OD600 $\geq 0.6$, BACs were purified using the Plasmid Midi prep kit (Qiagen, Hilden, Germany). 
BAC DNA was precipitated with ethanol and resuspended in $30 \mu \mathrm{l}$ of twice-distilled sterile water. BAC concentration was quantified using a Qubit fluorometer (Thermo Fisher Scientific, Waltham, MA, USA).

\section{Chromosomal microdissection and preparation of the painting probe}

A chromosome-specific probe of the largest submetacentric pair of $T$. pennellii was prepared by microdissection [86]. This chromosome pair is the only one that is easily distinguishable during dissection due to its large size (15 vs $5 \mu \mathrm{m}$ on average). Glass microneedles were made using a PC-100 pipette puller (Narishige, Tokyo, Japan). Chromosome capture was performed using a Zeiss inverted microscope (Zeiss, Oberkochen, Germany) and a Narishige model number micromanipulator (Narishige model PC-10, Tokyo, Japan). Metaphases of interest were covered with $10 \mu \mathrm{l}$ of sterile distilled water. The target chromosome pair was impaled by the needle tip and transferred to a $100 \mu \mathrm{l}$ PCR tube containing $10 \mu \mathrm{l}$ DNase-free water. After 30 chromosomal copies of the pair were collected, random DNA fragments were amplified by PCR using, 1) the Whole Genome Amplification WGA4 kit (Sigma-Aldrich, Saint-Louis, Mo, USA), followed by 2) the Whole Genome Reamplification WGA3 kit (Sigma-Aldrich) according to the manufacturer's instructions. Amplified DNA was quantified by fluorometry using the Qubit dsDNA HS (high-sensitivity) array kit (Thermo Fisher Scientific). The WGA4 kit yielded $\sim 4 \mu \mathrm{g}$ of product from an input of $100 \mathrm{pg}$ of chromosomal DNA, whereas the WGA3 kit gave $\sim 7 \mu \mathrm{g}$ of DNA from an input of $10 \mathrm{ng}$ of WGA4 product.

\section{Probe labeling}

BAC clones $(1 \mu \mathrm{g}$ DNA) were labeled with fluorochromes (fluorescein-ULS, rhodamine-ULS or Dyomics415-ULSdGTP) using PlatiniumBrightTM Nucleic Acid Labeling Kits (ULS 495-Green, ULS 550 Red/Orange, ULS 415 Blue; Leica Biosystems, Wetzlar, Germany) following the instructions provided by the supplier. Labeling was performed under low illumination to limit fading of the fluorochromes. Labeled BACs were precipitated using ethanol. BAC DNAs were collected by centrifugation (45 min at 13,500 rpm); and the DNA pellets were resuspended in hybridization buffer (50\% formamide/2X SSC/ $10 \%$ dextran sulfate) for double or triple BAC-FISH (final probe concentrations $=16 \mathrm{ng} / \mu \mathrm{l})$.

Chromosome-painting probes $(1 \mu \mathrm{g}$ DNA) were labeled with biotin-11-dUTP by random priming using the Biotin-High-Prime Kit (Roche Diagnostics, Meylan, France) according to the manufacturer's instructions. Labeled painting probes were prepared in hybridization buffer to give a final concentration of $16 \mathrm{ng} / \mu \mathrm{l}$ as described for BAC clones.

\section{Competitor and carrier DNAs}

To prevent nonspecific hybridization of highly and moderately repetitive sequences present in the BAC and painting probes to chromosomes, we prepared genomic DNA from $N$. coriiceps and T. hansoni as specific competitors following Bonillo et al. [87]. As carrier, we used DNA from the red deer, Cervus elaphus. DNA was extracted from muscle tissue following Winnepenninckx et al. [88]. DNA was then fragmented by thermal shock. Following centrifugations, DNA pellets were resuspended in hybridization buffer ( $50 \%$ formamide/2X SSC/ $10 \%$ dextran sulfate) to final concentrations of $8 \mu \mathrm{g} / \mu \mathrm{l}$ (N. coriiceps, T. hansoni) or $10 \mu \mathrm{g} / \mu \mathrm{l}$ (C. elaphus).

\section{Fish}

BAC-FISH and chromosomal painting were performed on chromosome preparations from 19 notothenioid species (Additional file 2) according to Bonillo et al. [87]. Due to limited numbers of chromosomal spreads for some species, we tested the hybridization efficiency of two BACs (C4 and F15) to all species. Results demonstrated high cross-hybridization efficiency (Fig. 3).

Briefly, labeled BAC or painting probes were denatured by heating at $85^{\circ} \mathrm{C}$ for $5 \mathrm{~min}$ in the presence of specific competitor and carrier DNA. Denatured BACs or painting probes were then incubated for $2 \mathrm{~h}$ at $37^{\circ} \mathrm{C}$ with competitor DNAs before applying them to freshly thawed and denatured $\left(72{ }^{\circ} \mathrm{C}, \quad 10-60 \mathrm{~s}, \quad 70 \%\right.$ formamide/2X SSC) chromosome preparations. Slides were incubated for $48 \mathrm{~h}$ at $37^{\circ} \mathrm{C}$ in a humid chamber, washed in appropriate buffers, and dehydrated by a succession of ethanol washes [87]. To ensure BAC and painting signal specificity, FISH was performed on chromosome preparations under high stringency washing conditions: $0.4 \mathrm{X}$ SSC, $0.3 \%$ Tween 20 at $60{ }^{\circ} \mathrm{C}$ for $2 \mathrm{~min}$, followed by $2 \mathrm{X} \mathrm{SSC}, 0.1 \%$ Tween 20 for $1 \mathrm{~min}$. For both BAC and painting probes, DNA was counterstained with DAPI/antifade.

For chromosomal painting, slides were covered with $40 \mu \mathrm{l}$ of FITC-avidin (Roche Diagnostics) under a $24 \times 40$ $\mathrm{mm}$ glass coverslip; incubated $5 \mathrm{~min}$ at $37^{\circ} \mathrm{C}$ in a humid chamber, and washed three times in 4X SSC, $1 \%$ Tween 20 at room temperature for $2 \mathrm{~min}$.

\section{Image acquisition}

FISH images were recorded using a Zeiss Axioplan microscope equipped with a cooled CCD camera (Coolsnap Photometrics, Tucson, AZ 85706, USA) and an $\mathrm{XCite}$ LED fluorescence light source. Karyotypes were processed using CytoVision 3.93.2/Genus FISH-imaging software for animal chromosomes (Leica Microsystems). Ten to 40 metaphase spreads per species were examined for each hybridized probe. 


\section{Supplementary information}

Supplementary information accompanies this paper at https://doi.org/10. 1186/s12862-020-1600-3.

Additional file 1. Complete list of the 40 BACs studied. The BACs are grouped according to the signal category: "specific", "repetitive" or "weak". SU locations, chromosomal positions and species examined for "specific" BACs are indicated.

Additional file 2. Species sampling for chromosomal preparations and for tissue (muscle) for DNA extraction. This file contains a table describing all the specimens' material used in this study.

\section{Abbreviations}

AFGPs: Antifreeze glycoproteins; BAC: Bacterial artificial chromosome; DAPI: 4',6-diamidino-2-phenylindole; FISH: Fluorescence in situ hybridization; FITC: Fluorescein isothiocyanate; ICHs: Interspecific chromosomal homologies; My: Million years; NORs: Nucleolus organizer regions; SU: Structural unit; TGD: Teleost genome duplication

\section{Acknowledgments}

We thank Thomas Desvignes for his kind help and constructive discussions all along this work. We are grateful to the Institut Polaire français Paul-Emile Victor (IPEV) and the U.S. National Science Foundation (NSF) (programs Icthyologie côtière en Terre Adélie (ICOTA 1996-2008) and Resources Ecologiques et Valorisation par un Observatoire à Long terme en Terre Adélie (REVOLTA 2010-2014)); to Collaborative East Antarctic Marine Census for the Census of Antarctic Marine Life (CAML-CEAMARC 2007-2008, IPY project no. 53) cruise on board the RV Aurora Australis; to International Collaborative Expedition to collect and study Fish Indigenous to Sub-antarctic Habitats, Atlantic sector of the Southern Ocean (ICEFISH 2004), on board the R.V. Nathaniel Palmer, and to POissons de KERguelen, shelf of Kerguelen-Heard islands (POKER 2006, 2010, 2013) on board the "Austral" trawler. We thank the crews and participants involved in the capture of the samples and chromosome preparations in different sectors of Antarctica and particularly M. Hautecoeur, G. Lecointre, H. D'Hont, S. Pavoine, C. Loots, O. Rey, J. Lanshere, T. Nebout, S. Iglesias, E. Pisano and C. Cheng and the captain and crew of the R.V. Nathaniel Palmer. We are grateful to E. Pisano and C. Cheng for additional samples, providing chromosomes of C. hamatus, C. antarcticus (stock of cytogenetic preparations for polar fishes organized by the CNR of Genoa, PNRA POLICY project), N. rossii, N. angustata, D. mawsoni. We thank the "Service de Systématique Moléculaire" (SSM, UMS 2700, MNHN/CNRS) for granting access to its technical platform and help. This is contribution 403 from the Marine Science Center at Northeastern University. This is ICEFISH publication 28. We also thank the editor and anonymous reviewers for their helpful comments.

\section{Authors' contribution}

JA, AD, CO-C, and DH conceived and designed research. JA and PG conducted experiments. OC was determinant for the microdissection and painting experiments and expertise. AA, JP and HWD were determinant in providing the $\mathrm{BAC}$ clone material. JA, $\mathrm{CO}-\mathrm{C}$, and $\mathrm{DH}$ analyzed data. JA wrote the manuscript. $\mathrm{DH}, \mathrm{OC}, \mathrm{CO}-\mathrm{C}, \mathrm{AD}, \mathrm{HWD}, \mathrm{AA}$ and JP helped to the manuscript revisions. All authors read and approved the manuscript.

\section{Funding}

We thank the Sorbonne Université (SU), the Centre National de la Recherche Scientifique (CNRS), the Museum National d'Histoire Naturelle (MNHN) and the Australian Antarctic Division (AAD) for financial support. We also thank the program "Interface pour le Vivant" (IPV, SU), and the two ATM bursaries (DetNo and DetNo2, MNHN) for the additional supports of this study. We thank National Institutes of Health (NIH) grants R01AG031922 from the National Institute on Aging (to J.H.P.), by 5R01OD011116 and R24RR032670 (to J.H.P.) from the NIH Office of the Director, and by NSF grants OPP0132032, ANT-0944517, PLR-1247510, and PLR-1444167 from the Office/Division of Polar Programs (to H.W.D.) and PLR-1543383 (to J.H.P. and H.W.D.). These NIH and NSF funding bodies played no role in the design of the study and collection, analysis, and interpretation of data and in writing the manuscript.

\section{Availability of data and materials}

All data generated or analyzed during this study are included in this published article (and its supplementary information files). The N. coriiceps
BAC library VMRC-19 [66-68] is available from J. H. Postlethwait and A. Amores on reasonable request.

\section{Ethics approval and consent to participate}

Ethical approval for all procedures was granted by the ethics committee of the Ministère de l'Environnement and the French Polar Research Institute (Institut Paul Emile Victor - IPEV), which approved all our fieldwork. Experiments complied with the Code of Ethics of Animal Experimentation in the Antarctic sector.

\section{Consent for publication}

Not applicable.

\section{Competing interests}

The authors declare that they have no competing interests.

\section{Author details}

'Sorbonne Université, CNRS, Université des Antilles, Evolution Paris Seine Institut de Biologie Paris Seine (EPS - IBPS), 75005 Paris, France. ${ }^{2}$ Institut de Systématique, Evolution, Biodiversité (ISYEB) - Muséum National d'Histoire Naturelle, CNRS, Sorbonne Université, EPHE, Université des Antilles, 43, rue Cuvier, 75231 Paris Cedex 05, France. ${ }^{3}$ Department of Marine and Environmental Sciences, Marine Science Center, Northeastern University, Nahant, MA 01908, USA. ${ }^{4}$ Institute of Neuroscience, Department of Biology, University of Oregon, Eugene, OR 97403, USA. ${ }^{5}$ Institut National de Recherche pour l'agriculture, I'alimentation et l'environnement, INRAE, UMR1349 IGEPP, Molecular cytogenetics Platform, BP35327, F-35653 Le Rheu Cedex, France.

Received: 13 August 2019 Accepted: 3 March 2020

Published online: 20 March 2020

\section{References}

1. Kennett JP. Cenozoic evolution of Antarctic glaciation, the circum-Antarctic Ocean, and their impact on global paleoceanography. J Geophys Res. 1977; 82:3843-60.

2. Anderson JB, Shipp SS, Lowe AL, Wellner JS, Mosola AB. The Antarctic ice sheet during the last glacial maximum and its subsequent retreat history: a review. Quat Sci Rev. 2002;21:49-70.

3. Huybrechts P. Sea-level changes at the LGM from ice-dynamic reconstructions of the Greenland and Antarctic ice sheets during the glacial cycles. Quat Sci Rev. 2002;21:203-31.

4. Thatje S, Hillenbrand C-D, Larter R. On the origin of Antarctic marine benthic community structure. Trends Ecol Evol. 2005;20:534-40.

5. Smale D, Barnes D, Fraser K, Peck L. Benthic community response to iceberg scouring at an intensely disturbed shallow water site at Adelaide Island. Antarctica Mar Ecol Prog Ser. 2008;355:85-94.

6. Duhamel $G$, Hulley P, Causse R, Koubbi P, Vacchi M, Pruvost $P$, et al. In: De Broyer C, Koubbi P, Griffiths HJ, Raymond B, Udekem d'Acoz C, editors. Biogegographic atlas of the Southern Ocean. Cambridge: Scientific Committee on Antarctic Research; 2014. p. 328-52.

7. Matschiner M, Hanel R, Salzburger W. On the origin and trigger of the Notothenioid adaptive radiation. PLoS One. 2011;6:1-9.

8. Near TJ, Dornburg A, Harrington RC, Oliveira C, Pietsch TW, Thacker CE, et al. Identification of the notothenioid sister lineage illuminates the biogeographic history of an Antarctic adaptive radiation. BMC Evol Biol. 2015;15 https://doi.org/10.1186/s12862-015-0362-9.

9. De Vries AL. Glycoproteins as biological antifreeze agents in Antarctic fishes. Science. 1971;172:1152-5.

10. De Vries A. Biological antifreezes and survival in freezing environments. In: Gilles R, editor. Animals and Environmental Fitness: Physiological and Biochemical Aspects of Adaptation and Ecology. Oxford: Pergamon Press, Elsevier Ltd; 1980. p. 583-607.

11. Di Prisco G, Cocca E, Parker SK, Detrich HW. Tracking the evolutionary loss of hemoglobin expression by the white-blooded Antarctic icefishes. Gene. 2002;295:185-91.

12. Near TJ, Parker S, Detrich WH III. A genomic fossil reveals key steps in hemoglobin loss by the Antarctic Icefishes. Mol Biol Evol. 2006;23:2008-16.

13. Cheng C, Detrich HW. Molecular ecophysiology of Antarctic notothenioid fishes. Philos Trans R Soc B: Biol Sci. 2007;362:2215-32. 
14. Near TJ, Dornburg A, Kuhn KL, Eastman JT, Pennington JN, Patarnello T, et al. Ancient climate change, antifreeze, and the evolutionary diversification of Antarctic fishes. Proc Natl Acad Sci. 2012;109:3434-9.

15. Near TJ, MacGuigan DJ, Parker E, Struthers CD, Jones CD, Dornburg A. Phylogenetic analysis of Antarctic notothenioids illuminates the utility of RADseq for resolving Cenozoic adaptive radiations. Mol Phylogenet Evol. 2018;129:268-79.

16. Dettai A, Berkani M, Lautredou A-C, Couloux A, Lecointre G, Ozouf-Costaz C, et al. Tracking the elusive monophyly of nototheniid fishes (Teleostei) with multiple mitochondrial and nuclear markers. Mar Genomics. 2012;8:49-58.

17. Colombo M, Damerau M, Hanel R, Salzburger W, Matschiner M. Diversity and disparity through time in the adaptive radiation of Antarctic notothenioid fishes. J Evol Biol. 2015:28:376-94.

18. Near TJ, Cheng C-HC. Phylogenetics of notothenioid fishes (Teleostei: Acanthomorpha): inferences from mitochondrial and nuclear gene sequences. Mol Phylogenet Evol. 2008;47:832-40.

19. Eastman J, McCune AR. Fishes on the Antarctic continental shelf: evolution of a marine species flock? J Fish Biol. 2000;57:84-102.

20. Rutschmann S, Matschiner M, Damerau M, Muschick M, Lehmann MF, Hanel $\mathrm{R}$, et al. Parallel ecological diversification in Antarctic notothenioid fishes as evidence for adaptive radiation: ecological diversification in Notothenioids. Mol Ecol. 2011;20:4707-21.

21. Lecointre G, Améziane N, Boisselier M-C, Bonillo C, Busson F, Causse R, et al. Is the species flock concept operational? Antarctic Shelf Case PLoS ONE. 2013:8:e68787.

22. Ozouf-Costaz C, Hureau J-C, Beaunier M. Chromosome studies on fish of the suborder Notothenioidei collected in the Weddell Sea during EPOS 3 cruise. Cybium. 1991;15:271-89

23. Morescalchi A, Pisano E, Stanyon R, Morescalchi MA. Cytotaxonomy of antarctic teleosts of the Pagothenia/Trematomus complex (Nototheniidae, Perciformes). Polar Biol. 1992;12:553-8.

24. Ghigliotti L, Cheng CC-H, Ozouf-Costaz C, Vacchi M, Pisano E. Cytogenetic diversity of notothenioid fish from the Ross Sea: historical overview and updates. Hydrobiologia. 2015;761:373-96.

25. Amores A, Wilson CA, Allard CAH, Detrich HW, Postlethwait JH. Cold Fusion: Massive Karyotype Evolution in the Antarctic Bullhead Notothen Notothenia coriiceps. G3 (Genes|Genomes|Genetics). 2017;7:2195-207.

26. Ozouf-Costaz C, Pisano E, Thaeron C, Hureau J-C. Antarctic fish chromosome banding: significance for evolutionary studies. Cybium. 1997;21:399-409.

27. Garagna S, Marziliano N, Zuccotti M, Searle JB, Capanna E, Redi CA. Pericentromeric organization at the fusion point of mouse Robertsonian translocation chromosomes. Proc Natl Acad Sci. 2001;98:171-5.

28. Eastman JT. The nature of the diversity of Antarctic fishes. Polar Biol. 2005; 28:93-107.

29. Jaillon O, Aury J-M, Brunet F, Petit J-L, Stange-Thomann N, Mauceli E, et al. Genome duplication in the teleost fish Tetraodon nigroviridis reveals the early vertebrate proto-karyotype. Nature. 2004;431:946-57.

30. Nakatani Y, Takeda H, Kohara Y, Morishita S. Reconstruction of the vertebrate ancestral genome reveals dynamic genome reorganization in early vertebrates. Genome Res. 2007;17:1254-65.

31. Sacerdot C, Louis A, Bon C, Berthelot C, Roest CH. Chromosome evolution at the origin of the ancestral vertebrate genome. Genome Biol. 2018;19 https://doi.org/10.1186/s13059-018-1559-1.

32. Ohno S. Evolution by gene duplication, vol. 9. New-York: Springer-Verlag; 1970. p. 160. http://doi.wiley.com/, https://doi.org/10.1002/tera.1420090224.

33. Hartley SE. The chromosomes of salmonid fishes. Biol Rev. 1987;62:197-214.

34. Postlethwait JH, Yan Y-L, Gates MA, Horne S, Amores A, Brownlie A, et al. Vertebrate genome evolution and the zebrafish gene map. Nat Genet. 1998; 18:345-9.

35. Postlethwait J, Amores A, Force A, Yan Y-L. The Zebrafish genome: Genetics and Genomics. Methods in Cell Biology. San Diego: Elsevier; 1999. p. 14963. https://doi.org/10.1016/S0091-679X(08)61898-1.

36. Naruse K, Hori H, Shimizu N, Kohara Y, Takeda H. Medaka genomics: a bridge between mutant phenotype and gene function. Mech Dev. 2004;121:619-28.

37. Woods IG. The zebrafish gene map defines ancestral vertebrate chromosomes. Genome Res. 2005;15:1307-14.

38. Kohn M, Hogel J, Vogel W, Minich P, Kehrersawatzki H, Graves J, et al. Reconstruction of a 450-my-old ancestral vertebrate protokaryotype. Trends Genet. 2006;22:203-10.

39. Amores A. Zebrafish hox clusters and vertebrate genome evolution. Science. 1998;282:1711-4
40. Taylor JS. Genome duplication, a trait shared by 22,000 species of ray-finned fish. Genome Res. 2003;13:382-90.

41. Hurley I, Hale ME, Prince VE. Duplication events and the evolution of segmental identity. Evol Dev. 2005;7:556-67.

42. Santini F, Harmon LJ, Carnevale G, Alfaro ME. Did genome duplication drive the origin of teleosts? A comparative study of diversification in ray-finned fishes. BMC Evol Biol. 2009;9:194.

43. Ocalewicz K. Cytogenetic analysis of platyfish (Xiphophorus maculatus) shows location of major and minor rDNA on chromosomes: cytogenetic analysis of platyfish. Hereditas. 2005;141:333-7.

44. Kasahara M, Naruse K, Sasaki S, Nakatani Y, Qu W, Ahsan B, et al. The medaka draft genome and insights into vertebrate genome evolution. Nature. 2007:447:714-9.

45. Ghigliotti L, Fevolden S-E, Cheng C-HC, Babiak I, Dettai A, Pisano E. Karyotyping and cytogenetic mapping of Atlantic cod (Gadus morhua Linnaeus, 1758). Anim Genet. 2012;43:746-52.

46. Miyaki K, Tabeta O, Kayano H. Karyotypes in six species of Pufferfishes genus Takifugu (Tetraodontidae, Tetraodontiformes). Fish Sci. 1995;61:594-8.

47. Ross JA, Urton JR, Boland J, Shapiro MD, Peichel CL. Turnover of sex chromosomes in the stickleback fishes (Gasterosteidae). PLoS Genet. 2009;5: e1000391.

48. Urton JR, McCann SR, Peichel CL. Karyotype differentiation between two stickleback species (Gasterosteidae). Cytogenet Genome Res. 2011;135:150_ 9.

49. Grutzner F, LuÈtjens G, Rovira C, Barnes DW, Ropers H-H, Haaf T. Classical and molecular cytogenetics of the pufferfish Tetraodon nigroviridis. Chromosom Res. 1999;7:655-62.

50. Mazzei F, Ghigliotti L, Lecointre G, Ozouf-Costaz C, Coutanceau J-P, Detrich $W$, et al. Karyotypes of basal lineages in notothenioid fishes: the genus Bovichtus. Polar Biol. 2006;29:1071-6.

51. Pisano E, Cocca E, Mazzei F, Ghigliotti L, Di Prisco G, Detrich HW III, et al. Mapping of $a$-and $\beta$-globin genes on Antarctic fish chromosomes by fluorescence in-situ hybridization. Chromosom Res. 2003;11:633-40.

52. Pisano E, Ozouf-Costaz C, Hureau JC, Williams R. Chromosome differentiation in the subantarctic Bovichtidae species Cottoperca gobio (Günther, 1861) and Pseudaphritis urvillii (Valenciennes, 1832) (Pisces, Perciformes). Antarct Sci. 1995;7:381-6.

53. Mazzei F, Ghigliotti L, Coutanceau J-P, Detrich HW, Prirodina V, Ozouf-Costaz C, et al. Chromosomal characteristics of the temperate notothenioid fish Eleginops maclovinus (Cuvier). Polar Biol. 2008;31:629-34.

54. Pisano E, Ozouf-Costaz C, Bonillo C, Caimo A, Rossetti S, Williams R. Cytogenetics of the Antarctic icefish Champsocephalus gunnari Lönnberg, 1905 (Channichthyidae, Notothenioidei). Comp Biochem Physiol A Physiol. 1997;118:1087-94

55. Morescalchi A, Morescalchi MA, Odierna G, Sitingo V, Capriglione T. Karyotype and genome size of zoarcids and notothenioids (Taleostei, Perciformes) from the Ross Sea: cytotaxonomic implications. Polar Biol. 1996; 16:559-64.

56. Caputo V, Splendiani A, Nisi Cerioni P, Olmo E. The chromosomal complement of the artedidraconid fish Histiodraco velifer (Perciformes: Notothenioidei) from Terra Nova Bay. Ross Sea Cytogenet Genome Res. 2003;101:29-32.

57. Pisano E, Ozouf-Costaz C. Chromosome change and the evolution in the Antarctic fish suborder Notothenioidei. Antarct Sci. 2000;12:334-42 https:// doi.org/10.1017/S0954102000000390.

58. Morescalchi A, Hureau JC, Olmo E, Ozouf-Costaz C, Pisano E, Stanyon R. A multiple sex-chromosome system in Antarctic ice-fishes. Polar Biol. 1992;11: 655-61 https://doi.org/10.1007/BF00237962.

59. Auvinet J, Graça P, Belkadi L, Petit L, Bonnivard E, Dettaï A, et al. Mobilization of retrotransposons as a cause of chromosomal diversification and rapid speciation: the case for the Antarctic teleost genus Trematomus. BMC Genomics. 2018;19 https://doi.org/10.1186/s12864-018-4714-X.

60. Auvinet J, Graça P, Ghigliotti L, Pisano E, Dettaï A, Ozouf-Costaz C, et al. Insertion hot spots of DIRS1 Retrotransposon and chromosomal diversifications among the Antarctic Teleosts Nototheniidae. Int J Mol Sci. 2019;20:19 https://doi.org/10.3390/ijms20030701.

61. Pisano E, Angelini C, Mazzei F, Stanyon R. Adaptive radiation in Antarctic notothenioid fish: studies of genomic change at chromosomal level. Ital J Zool. 2000;67:115-21.

62. Bush G. Modes of Animal Speciation. Annual Review of Ecology and Systematics. Ann Rev Ecol Systematics. 1975;6:339-64. 
63. White MJD. Modes of speciation in orthopteroid insects. Bolletino di zoologia. 1980;47:83-94.

64. Baker RJ, Bickham JW. Speciation by monobrachial centric fusions. Proc Natl Acad Sci. 1986:83:8245-8

65. Rieseberg LH. Chromosomal rearrangements and speciation. Trends Ecol Evol. 2001:16:351-8.

66. Detrich HW, Stuart A, Schoenborn M, Parker SK, Methé BA, Amemiya CT. Genome enablement of the notothenioidei: genome size estimates from 11 species and BAC libraries from 2 representative taxa. J Exp Zool B Mol Dev Evol. 2010;314B:369-81.

67. Detrich HW, Amemiya CT. Antarctic Notothenioid fishes: genomic resources and strategies for analyzing an adaptive radiation. Integr Comp Biol. 2010; 50:1009-17.

68. Shin SC, Ahn DH, Kim SJ, Pyo CW, Lee H, Kim M-K, et al. The genome sequence of the Antarctic bullhead notothen reveals evolutionary adaptations to a cold environment. Genome Biol. 2014;15:468.

69. Kim B-M, Amores A, Kang S, Ahn D-H, Kim J-H, Kim I-C, et al. Antarctic blackfin icefish genome reveals adaptations to extreme environments. Nat Ecol Evol. 2019;3:469-78.

70. Near TJ. Estimating divergence times of notothenioid fishes using a fossilcalibrated molecular clock. Antarct Sci. 2004;16:37-44.

71. White MJD. Cytogenetics of speciation. Aust J Entomol. 1970;9:1-6.

72. White MJD. Chain processes in chromosomal speciation. Syst Zool. 1978:27: 285.

73. Giles V, Thode G, Alvarez MC. A new Robertsonian fusion in the multiple chromosome polymorphism of a mediterranean population of Gobius paganellus (Gobiidae, Perciformes). Heredity. 1985;55:255-60.

74. Auffray J-C. Chromosomal divergence in house mice in the light of palaeontology: a colonization-related event? Quat Int. 1993;19:21-5.

75. Britton-Davidian J, Catalan J, da Graça RM, Ganem G, Auffray J-C, Capela R, et al. Rapid chromosomal evolution in island mice: environmental genetics. Nature. 2000:403:158.

76. Dobigny G, Ozouf-Costaz C, Bonillo C, Volobouev V. Evolution of rRNA gene clusters and telomeric repeats during explosive genome repatterning in Taterillus X (Rodentia, Gerbillinae). Cytogenet Genome Res. 2003;103:94-103.

77. Pialek J, Hauffe HC, Searle JB. Chromosomal variation in THE house mouse: chromosomal variation in the house mouse. Biol J Linn Soc. 2005;84:535-63.

78. Kitano J, Ross JA, Mori S, Kume M, Jones FC, Chan YF, et al. A role for a neosex chromosome in stickleback speciation. Nature. 2009;461:1079-83.

79. Tomaszkiewicz M, HauTecoeur M, Coutanceau JP, Bonillo C, Dettaï A, Mazzei F, et al. Comparative cytogenetic studies of the Nototheniidae (Teleostei: Acanthomorpha) from the Indian (Kerguelen-Heard Plateau) and Atlantic (South Georgia, South Sandwich, Falkland/Malvinas, Bouvet Islands) sectors of the Southern Ocean. Cytogenet Nototheniids Ind Atl South Ocean. 2011; 35:109-21.

80. Lautrédou A-C, Hinsinger DD, Gallut C, Cheng C-HC, Berkani M, OzoufCostaz C, et al. Phylogenetic footprints of an Antarctic radiation: the Trematominae (Notothenioidei, Teleostei). Mol Phylogenet Evol. 2012;65:87101.

81. Vaughan DG, Marshall GJ, Connolley WM, Parkinson C, Mulvaney R, Hodgson DA, et al. Recent Rapid Regional Climate Warming on the Antarctic Peninsula. Clim Chang. 2003;32:243-74

82. Meredith MP, King JC. Rapid climate change in the ocean west of the Antarctic Peninsula during the second half of the 20th century: rapid ocean climate change at the wap. Geophys Res Lett. 2005;32:L19604.

83. Steig EJ, Schneider DP, Rutherford S, Mann MEE, Comiso JC. Warming of the Antarctic ice-sheet surface since the 1957 International Geophysical Year. Nature. 2009:8:459-62.

84. Constable AJ, Melbourne-Thomas J, Corney SP, Arrigo KR, Barbraud C, Barnes DKA, et al. Climate change and Southern Ocean ecosystems I: how changes in physical habitats directly affect marine biota. Glob Chang Biol. 2014;20:3004-25.

85. Rey O, d'Hont A, Coutanceau J, Pisano E, Chilmonczyk S, Ozouf-Costaz C. Cephalic Kidney and Spleen Cell Culture in Antarctic Teleosts. In: OzoufCostaz C, Pisano E, Foresti F, de Almeida L, editors. Fish Cytogenetic Techniques: CRC Press; 2015. p. 74-81. https://doi.org/10.1201/b18534-12.

86. Guan XY, Meltzer PS, Trent JM. Rapid generation of whole chromosome painting probes (WCPs) by chromosome microdissection. Genomics. 1994; 22:101-7.
87. Bonillo C, Coutanceau JP, D'Cotta H, Ghigliotti L, Ozouf-Costaz C, Pisano E. Standard Fluorescence in situ Hybridization Procedures. Fish Cytogenet Tech: Ray-Fin Fishes Chondrichthyans. 2015:103-17.

88. Winnepennincks B, Backeljau T, De Watcher R. Extraction of high molecular weight DNA from molluscs. Trends Genet. 1993;9:407.

\section{Publisher's Note}

Springer Nature remains neutral with regard to jurisdictional claims in published maps and institutional affiliations.

\section{Ready to submit your research? Choose BMC and benefit from:}

- fast, convenient online submission

- thorough peer review by experienced researchers in your field

- rapid publication on acceptance

- support for research data, including large and complex data types

- gold Open Access which fosters wider collaboration and increased citations

- maximum visibility for your research: over $100 \mathrm{M}$ website views per year

At BMC, research is always in progress.

Learn more biomedcentral.com/submissions 